\title{
CHANGE OF ONOMASTIC UNITS: THE POSSIBILITY OF REFLECTION IN TOURISM DISCOURSE ${ }^{1}$
}

\author{
Dmitriy Yu. Ilyin \\ Volgograd State University, Volgograd, Russia
}

\begin{abstract}
Absract. The article reveals the changes in the names of geographical objects in the Volgograd Region due to extralinguistic and intralinguistic factors. The relevance of the study is determined by the need to present the dynamics of the development of the onomastic language subsystem in the socio-cultural aspect, which is important and necessary for the implementation of tourism activities. The material for study was urban names of Volgograd region.

To the most significant extralinguistic reasons affecting transformation of the name of a geographical object the author refers: the change in the state of society associated with political events, the desire to perpetuate in the name the memory of historical personalities who have made a definite contribution to the history, culture of the whole country or its particular region, specific settlement localization, the explication of which contributed to the individualization of the oikonym, the desire to reflect in the name of the settlement the features of economic living standards or the nature of industrial production. Among the intralinguistic factors that determine the renaming of a geographical object are the rejection of dialect words in the name of the settlement due to their archaization, the cacophony of the names of settlements and the urge to unification of the toponym according to the onomastics word formation model, typical for modern Russian.

It is concluded that the inclusion of information on the renaming of settlements and the explanation of the reasons for this process in the texts of tourist discourse will make it possible to realize the needs of the tourist in expanding their competences while developing another socio-communicative space.

Key words: onomastics, toponymy, nomination, discourse, tourist discourse, language of the region.

Citation. Ilyin D.Yu. Change of Onomastic Units: the Possibility of Reflection in Tourism Discourse. Vestnik Volgogradskogo gosudarstvennogo universiteta. Seriya 2, Yazykoznanie [Science Journal of Volgograd State University. Linguistics], 2017, vol. 16, no. 4, pp. 129-136. (in Russian). DOI: https://doi.org/10.15688/jvolsu2.2017.4.11
\end{abstract}

\section{ИЗМЕНЕНИЕ ОНОМАСТИЧЕСКИХ ЕДИНИЦ: ВОЗМОЖНОСТИ ОТРАЖЕНИЯ В ТУРИСТИЧЕСКОМ ДИСКУРСЕ ${ }^{1}$}

\author{
Дмитрий Юрьевич Ильин \\ Волгоградский государственный университет, г. Волгоград, Россия
}

\begin{abstract}
Аннотация. В статье выявлены изменения наименований географических объектов Волгоградской области, обусловленные экстралингвистическими и интралингвистическими факторами. Актуальность исследования определяется необходимостью представить динамику развития ономастической подсистемы языка в социолькультурном аспекте, важном для осуществления туристической деятельности. Материалом для ․ изучения послужили урбанонимические названия Волгоградской области.

К наиболее существенным экстралингвистическим причинам, влияющим на трансформацию названия географического объекта, автор относит изменения в состоянии общества, сопряженные с политическими событиями, стремление увековечить в наименовании память об исторических личностях, внесших определенный вклад в историю, культуру всей страны или отдельного ее региона, специфическую локализацию населенного пункта, экспликация которой способствовала индивидуализации ойконима, стремление отразить в названии особенности хозяйственной жизни населения или характер распространенного в пределах
\end{abstract}


поселения промышленного производства. В ряду интралингвистических факторов, определяющих переименование географического объекта, выделяются отказ от диалектных слов в наименовании поселения в силу их архаизации, неблагозвучие названий населенных пунктов, унификация топонима по типичной для ономастики словообразовательной модели, распространенной в современном русском языке.

Делается вывод о том, что включение в тексты туристического дискурса сведений о переименовании населенных пунктов и объяснение причин этого процесса позволит реализовать потребности туриста в расширении его компетенций при освоении другого социокоммуникативного пространства.

Ключевые слова: ономастика, топонимика, номинация, дискурс, туристический дискурс, язык региона.

Цитирование. Ильин Д. Ю. Изменение ономастических единиц: возможности отражения в туристическом дискурсе // Вестник Волгоградского государственного университета. Серия 2, Языкознание. - 2017. T. 16, № 4. -C. 129-136. - DOI: https://doi.org/10.15688/jvolsu2.2017.4.11

1

Изучение формирования глобализованного туристического дискурса дает возможность представить динамику развития общества в социокультурном аспекте, поскольку именно в туристической деятельности «находит выражение одобрение сосуществования культур в индивидуальном опыте» [Митягина, 2016, с. 10]. Принимая во внимание тот факт, что качество восприятия путешественником языковых единиц иного социокоммуникативного пространства влияет на формирование образа другой (чужой) страны или другого (чужого) региона в сознании туристов, способствует стереотипизации инокультурных реалий, подчеркнем комплексность туристического дискурса как феномена, объединяющего многие разновидности дискурсов. Лингвистическое осмысление туристического дискурса приводит к мысли о целесообразности включения в тексты для потребителей услуги (путеводители, энциклопедические статьи и книги о странах, городах, достопримечательностях, статьи в газетах и журналах, информация на сайтах туристических агентств и т. п.) безэквивалетной лексики, частью которой являются ономастические названия, хранящие «презумпцию осмысленности и надежду на ее реализацию - на раскрытие скрытого смысла» [Топоров, 2004, с. 374]. Полагаем, что интерес у путешественников могут вызвать случаи переименования населенных пунктов, вызванные как экстра-, так и интралингвистическими причинами.

Анализ специальной литературы свидетельствует о том, что основное внимание исследователей сосредоточено на изучении изменений, происходивших и происходящих во внутригородской топонимике - урбанонимике. В подобного рода работах немалое значение имеет описание географических объектов в аспекте туристической деятельности (см., напр.: [Беликов, 2005; Горбаневский, 1991; Китайгородская, Розанова, 2000; Нерознак, Горбаневский, 1991; Поберезкина, 2003; Топоров, 1991]), в сферу которой попадают и топонимические словари, представляющие богатый материал для знакомства с разными туристическими объектами на территории России [Городские имена..., 1990; Ливинская, 2015; Поспелов, 2008; Русская ономастика..., 1994]. В то же время при всем многообразии проводимых разноаспектных исследований процессы, объясняющие разнообразные изменения в процессе номинации топонимических объектов и характеризующие онтологические основы формирования различных групп региональных названий, изучены недостаточно, работы по этой проблематике единичны [Ильин, 2016; Кудряшова, 2002; Никитин, 2010]. В результате отсутствует полное представление о комплексе факторов разного порядка, участвующих в создании регионального топонимикона и влияющих на его функционирование.

Проблема трансформации названия как одного из процессов искусственной номинации, как показано А.К. Матвеевым, «имеет три стороны: политическую (шире - идеологическую), которая вызывает переименование, экономическую (финансовую), которая его обеспечивает, и языковую (топонимическую), которая обусловливает вхождение, встраивание названия в топонимическую систему, его соответствие нормам языка и культурно-эстетическому идеалу» [Матвеев, 2009, с. 101]. Следовательно, изменение топонимических 
названий может быть связано как с экстралингвистическими факторами, так и с причинами внутриязыкового характера. Экспликация таких сведений в туристическом дискурсе позволит, на наш взгляд, расширить представления туристов о разных регионах России, об их культурной специфике и роли в истории страны.

\section{2}

Культурно-исторический интерес у туристов может вызвать информация о населенных пунктах, названия которых подверглись изменениям по причине каких-либо исторических событий, значимых для жизни социума либо государства: «Поскольку меняются условия социокультурной жизни (создаются новые предметы и идеи, меняются социальные отношения и т. п.), людям приходится переопределять изменяющиеся элементы своего окружения, перераспределять их места в собственной картине мира, то есть "переоценивать ценности"» [Арнольдов, 1987, с. 24].

2.1. Одной из основных причин переименования населенного пункта может служить изменение в состоянии общества, связанном с какими-либо политическими событиями. В качестве наиболее яркого примера такого рода трансформаций можно привести название областного центра, которое менялось дважды [Поспелов, 2008, с. 143-144]. Основанный в 1589 г., первые 336 лет своего существования он именовался Царицын. В 1925 г. город был переименован в Сталинград, поскольку руководитель Советского государства принимал участие в становлении новой власти в нашем регионе. Разоблачение культа личности во время кампании десталинизации привело к тому, что в 1961 г. город получил нейтральное наименование Волгоград, созданное по типичной для топонимов модели, отражающей объективные признаки поселения (город, стоящий на берегу реки - Волги).

Показателен в данном отношении и другой пример переименования, связанный с политикой и идеологией государства. В связи с началом первой мировой войны Министерство внутренних дел России 15 октября 1914 г. распорядилось ликвидировать географические названия, этимология которых восходила к не- мецкому языку. В Царицынском уезде - территории проживания немецких религиозных общин еще со времен правления Екатерины II - все населенные пункты, имеющие подобную номинативную основу, были переименованы. «Царицынский вестник» - ежедневная общественно-политическая газета, издававшаяся в Царицыне с 1897 по 1917 гг. - прямо писала об этом: Губ<ернское > присутствіе постановило: село Маріенфельдъ, въ память изарствованія императора Николая I-го, когда село это было основано, наименовать Николаевскимъ, Александерсталь, ввиду полученія имъ этого наименованія въ память императора Александра II - Александровскимъ, Нейбальцерв по имени происхожденія близъ него речки «Перевозинки», наименовать - «Перевозинкой», Лизандердорфъ, ввиду расположенія его вблизи уезда - «Пограничнымъ» $u$ «Нейденгофъ", ввиду того что оно является выселками более стараго села, наименовать «Новымъ» (Царицынский вестник, 24.01.1915).

Говоря о региональном топонимиконе, следует назвать появление идеологически окрашенных наименований как отклик на реакцию местной власти на события 1917 г. и дальнейшее становление коммунистического строя. Так, основанный в 1897 г. поселок Новоалексеевский в 1957 г., в год 40-летия Советской власти, получил название nоселок Октябрьский, а расположенный в Урюпинском районе Волгоградской области $x y$ тор Моргунов, названный по фамилии его основателя, купца, построившего паровую мельницу на месте будущего поселения, получил номинацию хутор Первомайский, внутренняя форма которой эксплицирует название одного из главных политических праздников в СССР.

Таким образом, переименование по идеологическим мотивам представляет собой сложный лингвокультурный процесс, который, по нашему представлению, может быть репрезентирован в туристической информации с целью показать роль региона в истории страны и, наоборот, отражение истории страны в топонимике региона.

2.2. В ряду экстралингвистических причин, обусловивших переименование населен- 


\section{РАЗВИТИЕ И ФУНКЦИОНИРОВАНИЕ РУССКОГО ЯЗЫКА}

ного пункта, находится и стремление увековечить в названии память об исторических личностях, внесших определенный вклад в историю, культуру всей страны или отдельного ее региона. Подобные меморативы [Подольская, 1988, с. 79] распространены и в коммуникативном пространстве Волгоградской области. В частности, станица $\mathrm{Ycmb}_{\mathrm{cm}}$ Медведиикая - административная единица Области Войска Донского Российской империи - в 1933 г. была преобразована в город Серафимович и названа в честь уроженца этого населенного пункта известного советского писателя А.С. Серафимовича [Наш край..., 1973, с. 399]. Однако в силу неоднозначного восприятия местными жителями данного переименования, а также в связи с изменением общественно-политического строя, сопряженного со сменой настроений в социуме, в текстах современных газет одновременно фиксируются два названия географического объекта с необходимыми уточнениями и пояснениями: Творческую группу уже ждали в Усть-Медведицкой (Серафимовиче). Усть-медвединиы не могут простить земляку, что при жизни он воздвиг «памятник» самому себе, отняв историческое имя у родной станицы (Волгоградская правда, 01.10.1998).

Другой пример связан с названием одного из районных центров области - станииы Преображенской, входившей в Хоперский округ Области Войска Донского, которая в 1936 г. была переименована в поселок Киквидзе как дань памяти Василию Киквидзе участнику гражданской войны, начальнику дивизии, участвовавшей в боях с белоказаками на Дону [Поспелов, 2008, с. 227], но в 1997 г. в силу протестного настроения местных жителей населенному пункту было возвращено исконное название.

Как видим, переименованиям в честь политических деятелей в советское время подвергались населенные пункты, связанные с историей казачества; таким образом, повидимому, решалась задача уничтожения исторической памяти о казачьем военном сословии, представители которого неоднозначно воспринимали советскую власть не только в период ее установления, но и во все время ее существования.
2.3. Причиной для изменения названия могла служить специфическая локализация населенного пункта, экспликация которой индивидуализировала ойконим. В частности, в Дубовском районе Волгоградской области находится станица Суводская, которая была основана после Пугачевского восстания в 1783 г. волжскими казаками. Сначала населенный пункт имел название станица Александровская. Местное население, учитывая характерные особенности окружающего станицу ландшафта и протекающей рядом реки, стало частотно в устной речи употреблять название Суводское, образованное от суводь «круговоротъ, пучина, водоверть, водоворот, водокрут, заверть» (Даль, т. IV, с. 613). Впоследствии областные власти официально изменили название поселения.

Другой населенный пункт, название которого может вызвать интерес у путешественников, - основанная в начале XIX в. Калмыцкая колония, получившая такое наименование в связи с переселением калмыков, обращенных в христиан. Впоследствии поселение было переименовано в хутор Каменный Буерак, поскольку местность была изрезана буераками, то есть небольшими сухими оврагами (Даль, т. I, с. 335). Наконец, село Райгород, возникшее в 1779 г. и расположенное в Светлоярском районе, ранее именовалось Поповицкое, получило название от сочетания Райский городок, так как окружающие места были богаты растительностью, плодовыми деревьями, что ассоциировалось у верующих людей с Раем как местом блаженства.

2.4. Экстралингвистическими причинами было вызвано переименование населенного пункта, основанного в 1699 г., - слобода $У_{c \text { - }}$ пенская. Связано это было с целью отразить в ойкониме особенности хозяйственной жизни населения, характер распространенного в пределах поселения промышленного производства. Населенный пункт в середине XVIII в. стал называться Рудня, поскольку недалеко от него был открыт завод «сыродутой» руды [Поспелов, 2008, с. 380]. Как видим, в выборе этого наименования отразилась смена принципа номинации: населенный пункт назван не по имени расположенной в нем церкви (в Рудне - это самая древняя в Камышинском уезде деревянная Успенская цер- 
ковь), а по особенностям хозяйственной деятельности.

\section{3}

Изменение названий населенных пунктов может быть вызвано причинами интралингвистического характера.

3.1. Желание уйти от диалектных черт в наименовании поселения, которые, по наивным представлениям, устарели, архаизировались, обусловило переименование хутора Подкаравичи, название которому дало распространенное в местности дерево - караич - «вяз лиственный, берест» (БТСДК, с. 209). Населенный пункт был переименован в хутор Bmoрая Березовка в связи с обильным произрастанием березы в нем и на прилегающих к нему землях. По аналогичным этой причинам был переименован поселок Дудаченский, название которого образовано от диалектного $\partial y$ дак - «дрофа», он получил впоследствии номинацию поселок Нежинский.

3.2. В ряду причин внутриязыкового характера, способствующих трансформации ойконимов, можно отметить и неблагозвучие названий населенных пункта. В частности, долгое время на территории современной Волгоградской области находился хутор Вчерашние Щи, получивший такую номинацию от названия местного трактира. Стилистически сниженная окраска онима, постоянные насмешки проезжающих в адрес местных жителей послужили причинами появления нового названия - хутор Калиновка.

В качестве примера переименования по лингвоэтическим причинам можно привести и название расположенного в Калачевском районе поселения - хутор Самодуровка. После постройки Волго-Донского канала и образования Цимлянского водохранилища местные жители выступили за новое название географического объекта - Морской.

Следовательно, за эмоциональной мотивированностью смены названия населенного пункта может скрываться стремление изменить ассоциативные связи прежнего наименования.

3.3. Существенной причиной внутриязыкового свойства при номинации географического объекта может служить и переход топо- нима на типичную для ономастики словообразовательную модель, распространенную в русском языке. В качестве примера можно привести ойконим станиц̧а Устинская: населенный пункт получил название станица Усть-Бузулукская, в котором внутренняя форма связывается с географическим термином yстье - «место впадения реки (в море, озеро и т. п.), конечный участок нижнего течения реки» (MAC, т. 4, с. 528). Данное переименование обусловлено унификацией деривационных элементов по типу других населенных пунктов региона (Усmь-Грязнуха, Усть-Хоперская), где имеется указание не только на устье, но и на название реки, по берегам которой основано поселение.

\section{4}

Таким образом, номинативные процессы в сфере топонимической лексики могут быть обусловлены различными факторами при ведущей роли экстралингвистических причин. При переименовании населенных пунктов принимались во внимание такие критерии, как уникальность, информативность, историчность, эстетичность, приспособленность к фонетике и морфологии языка.

Феномен переименования представляется важным при информировании туристов, приезжающих в Волгоградскую область: объяснение причин переименования населенных пунктов позволит реализовать потребности туриста в развитии, расширении его личных возможностей и лингвистических компетенций, сыграть в текстах туристического дискурса разной жанровой отнесенности роль своеобразного «пропуска» в иную культуру, в другое социокоммуникативное пространство.

\section{ПРИМЕЧАНИЕ}

${ }^{1}$ Исследование выполнено при финансовой поддержке Российского фонда фундаментальных исследований (РФФИ) и Администрации Волгоградской области, проект № 17-14-34001 a(p) «Региональный туризм как фактор формирования дискурса и технологии перевода: номинативные и коммуникативно-прагматические конвенции текстов брендинга». 


\section{СПИСОК ЛИТЕРАТУРЫ}

Арнольдов А. И., 1987. Теория культуры: историзм и вопросы методологии (вместо введения) // Культура: человек и картина мира. М. : Наука. C. 5-27.

Беликов В. И., 2005. Языковая политика в топонимии как воспитание чувств и ее отражение в справочных изданиях как зеркало государственных эмоций // Эмоции в языке и речи : сборник научных статей / под ред. И. А. Шаронова. М. : РГГУ. С. 236-250.

Горбаневский М. В., 1991. Национальные образы в топонимии Москвы // Топонимика и межнациональные отношения. М. : МФГО. C. $25-40$.

Городские имена вчера и сегодня: Ленинградская топонимика, 1990. Сост. С. Алексеева, А. Владимирович, А. Ерофеев и др. Л. : ЛИК. 160 с.

Ильин Д. Ю., 2016. Региональные топонимические названия в туристическом дискурсе // Вестник Волгоградского государственного университета. Серия 2, Языкознание. Т. 15, № 4. C. 152-158. DOI: https://doi.org/10.15688/ jvolsu2.2016.4.15

Китайгородская М. В., Розанова Н. Н., 2000. Современная городская коммуникация: тенденции развития (на материале языка Москвы) // Русский язык конца ХХ столетия (1985-1995). 2-е изд. М. : Языки русской культуры. С. 345-383.

Кудряшова Р. И., 2002. Причины переименования населенных пунктов Волгоградской области // Ономастика Поволжья: Тез. докл. IX междунар. конф. (Волгоград, 9-12 сент. 2002 г.) / отв. ред. В. И. Супрун. Волгоград : Перемена. С. 161-163.

Ливинская И. В., 2015. «Словарь региональной лексики и неофициальных топонимов г. Новосибирска»: основные принципы и этапы составления // Вестник Волгоградского государственного университета. Серия 2, Языкознание. Т. 14, № 5. С. 40-45. DOI: http://dx.doi.org/ 10.15688/jvolsu2.2015.5.5

Матвеев А. К., 2009. Тенденции и практики в современной российской урбонономинации // Вопросы ономастики. № 7. С. 100-105.

Митягина В. А., 2016. Логистика многоязычного туристического ресурса: межкультурный дискурс в координатах глобализации // Лингвистическая и транслатологическая логистика многоязычного туристического интернет-ресурса [Текст] : коллектив. моногр. / авт. коллектив: В. А. Митягина (отв. ред.) [и др.] ; под общ. ред. д-ра филол. наук, проф. В. А. Митягиной. Волгоград : Изд-во ВолГУ. С. 9-25.
Наш край. Хроника истории Волгограда и области, 1973. Волгоград : Ниж.-Волж. кн. изд-во. $256 \mathrm{c}$.

Нерознак В. П., Горбаневский М. В., 1991. Советский «новояз» на географической карте: (О штампах и стереотипах речевого мышления). М. : Знание. 94 с.

Никитин С. А., 2010. Динамические процессы в современной русской топонимической системе // Русский язык: исторические судьбы и современность: IV Международный конгресс исследователей русского языка (Москва, 2023 марта 2010 г.) : Труды и материалы / составители М. Л. Ремнева, А. А. Поликарпов. М. : Изд-во Моск. ун-та. С. 811.

Поберезкина Л. 3., 2003. Современная городская среда и языковая политика // Русский язык сегодня : сб. статей / отв. ред. Л. П. Крысин. М. : Азбуковник. Вып. 2. С. 511-528.

Подольская Н. В., 1988. Словарь русской ономастической терминологии. 2-е изд., перераб. и доп. М. : Наука. 192 с.

Поспелов Е. М., 2008. Географические названия России : топонимический словарь : более 4000 единиц. М. : АСТ : Астрель. 528 с.

Русская ономастика и ономастика России, 1994. Словарь / Под ред. О. Н. Трубачева. М. : Школа-пресс. 288 с.

Топоров В. Н., 1991. Об одной топонимической катастрофе // Исторические названия - памятники культуры : сб. мат-лов II Всесоюз. науч.практ. конф. М. : Наука. Вып.1. С. 9-18.

Топоров В. Н., 2004. Из теоретической ономатологии // Исследования по этимологии и семантике. М. : Языки славянской культуры. Т. 1. C. 372-379.

\section{СЛОВАРИ}

БТСДК - Большой толковый словарь донского казачества: Ок. 18000 слов и устойчивых словосочетаний. М. : Русские словари : Издательство Астрель : Издательство АСТ, 2003.608 с.

Даль - Даль В. И. Толковый словарь живого великорусского языка : в 4 т. М. : АО Издательская группа «Прогресс», «Универс», 1994. Т. 4.864 с.

$M A C$ - Словарь русского языка : в 4 т. / под ред. А. П. Евгеньевой. 2-е изд., испр. и доп. М. : Русский язык, 1981-1984.

\section{REFERENCES}

ArnoldovA.I., 1987. Theory of culture: historicism and methodology (instead of introduction). Kultura: 
chelovek i kartina mira. Moscow, Nauka Publ., pp. 5-27. (in Russian).

Belikov V.I., 2005. Language policy in toponymy as education of feelings, and its reflection in reference publications as a mirror of state emotions. Sharonov I.A., ed. Emotsii v yazyke $i$ rechi: Sbornik nauchnykh statey. Moscow, RGGU Publ., pp. 236-250. (in Russian).

Gorbanevskiy M.V., 1991. National images in the toponymy of Moscow. Toponimika $i$ mezhnatsionalnye otnosheniya. Moscow, MFGO Publ., pp. 25-40. (in Russian).

Alekseeva S., Vladimirovich A., Erofeev A. eds. City names yesterday and today: Leningrad toponymy, 1990. Leningrad, LIK Publ. 160 p. (in Russian).

Ilyin D.Yu., 2016. Regional Toponyms in Tourism Discourse. Vestnik Volgogradskogo gosudarstvennogo universiteta. Seriya 2, Yazykoznanie [Science Journal of Volgograd State University. Linguistics], vol. 15, no. 4, pp. 152-158. DOI: https://doi.org/10.15688/ jvolsu2.2016.4.15 (in Russian).

Kitaygorodskaya M.V., Rozanova N.N., 2000. Modern urban communication: development trends (based on the material of the language of Moscow). Russkiy yazyk kontsa XX stoletiya (1985-1995). $2^{\text {nd }}$ ed. Moscow, Yazyki russkoy kultury Publ., pp. 345-383. (in Russian).

Kudryashova R.I., 2002. Reasons for renaming settlements in the Volgograd Region. Suprun V.I., ed. Onomastika Povolzhya: Tez. dokl. 9 mezhdunar. konf. (Volgograd, 9-12 September 2002). Volgograd, Peremena Publ., pp. 161-163. (in Russian).

Livinskaya I.V, 2015. Dictionary of Regional Vocabulary and Informal Toponyms of Novosibirsk: Principles of Arrangement and Stages of Composing. Vestnik Volgogradskogo gosudarstvennogo universiteta. Seriya 2, Yazykoznanie [Science Journal of Volgograd State University. Linguistics], no. 5 (29), pp. 4045. (in Russian). DOI: http://dx.doi.org/10.15688/ jvolsu2.2015.5.5

Matveev A.K., 2009. Tendencies and practices in modern Russian Urban Nomination. Voprosy onomastiki [Problems of Onomastics], no. 7, pp. 100-105. (in Russian).

Mityagina V.A., 2016. Logistics of a multilingual tourist resource: intercultural discourse in the context of globalization. Mityagina V.A., ed. Lingvisticheskaya $i$ translatologicheskaya logistika mnogoyazychnogo turisticheskogo internet-resursa. Volgograd, Izd-vo VolGU, pp. 925. (in Russian).

Our land. Chronicle of the history of Volgograd and the Volgograd region, 1973. Volgograd, Nizh.Volzh. Publ. 256 p. (in Russian).

Neroznak V.P, Gorbanevskiy M.V., 1991. Soviet "newlanguage" on a geographical map: (On stamps and stereotypes of speech thinking). Moscow, Znanie Publ. 94 p. (in Russian).

Nikitin S.A., 2010. Dynamic processes in the modern Russian toponymic system. Remneva M.L., Polikarpov A.A., eds. Russkiy yazyk: istoricheskie sudby $i$ sovremennost: IV Mezhdunarodnyy kongress issledovateley russkogo yazyka (Moscow, Lomonosov MSU, 20-23 March 2010): Trudy i materialy. Moscow, Izd-vo Mosk. un-ta, p. 811. (in Russian).

Poberezkina L.Z., 2003. Modern urban environment and language policy. Krysin L.P., ed. Russkiy yazyk segodnya. Vyp. 2. Sb. statey. Moscow, Azbukovnik Publ., pp. 511-528. (in Russian).

Podolskaya N.V., 1988. Dictionary of Russian onomastic terminology. $2^{\text {nd }}$ ed. Moscow, Nauka Publ. 192 p. (in Russian).

Pospelov E.M., 2008. Geographical names of Russia: toponymic dictionary. Moscow, AST, Astrel Publ. 528 p. (in Russian).

Trubachev O.N., ed. Russian onomastics and onomastics of Russia, 1994. Moscow, Shkolapress. 288 p. (in Russian).

Toporov V.N., 1991. About a toponymic catastrophe. Istoricheskie nazvaniya - pamyatniki kultury: Sb. mat-lov II Vsesoyuz. nauch.-prakt. konf. Moscow, Nauka Publ., vol. 1, pp. 9-18. (in Russian).

Toporov V.N., 2004. From theoretical onomatology. Issledovaniya po etimologii i semantike. Moscow, Yazyki slavyanskoy kultury Publ., vol. 1, pp. 372-379. (in Russian).

\section{DICTIONARIES}

Great explanatory dictionary of the Don Cossacks, 2003. Moscow, Russkie slovari Publ.; AST Publ. $608 \mathrm{p}$.

Dal V.I. Explanatory dictionary of the living Great Russian language. Vol. 4, 1991. Moscow, Progress Publ. 864 p.

Evgenyeva A.P., ed. Dictionary of Russian, 1981-1984. Moscow, Russkiy yazyk Publ. 


\section{РАЗВИТИЕ И ФУНКЦИОНИРОВАНИЕ РУССКОГО ЯЗЫКА}

\section{Information about the Author}

Dmitriy Yu. Ilyin, Doctor of Sciences (Philology), Associate Professor, Head of Department of Russian Filology, Volgograd State University, Prosp. Universitetsky, 100, 400062 Volgograd, Russia, dilyin@volsu.ru, dilyin99@mail.ru, https://orcid.org/0000-0001-6387-757X

\section{Сведения об авторе}

Дмитрий Юрьевич Ильин, доктор филологических наук, доцент, заведующий кафедрой русской филологии, Волгоградский государственный университет, просп. Университетский, 100, 400062 г. Волгоград, Россия, dilyin@volsu.ru, dilyin99@mail.ru, https://orcid.org/0000-0001-6387-757X 